\title{
Temas rituales en la cerámica « tipo códice » del estilo mixteca-puebla
}

Gilda Hernández Sánchez

\section{(2) OpenEdition \\ Journals}

Edición electrónica

URL: https://journals.openedition.org/jsa/1322

DOI: $10.4000 /$ jsa. 1322

ISSN: 1957-7842

Editor

Société des américanistes

\section{Edición impresa}

Fecha de publicación: 5 junio 2004

Paginación: 7-34

ISSN: 0037-9174

\section{Referencia electrónica}

Gilda Hernández Sánchez, «Temas rituales en la cerámica « tipo códice » del estilo mixteca-puebla», Journal de la Société des américanistes [En línea], 90-2 | 2004, Publicado el 05 junio 2009, consultado el 02 septiembre 2022. URL: http://journals.openedition.org/jsa/1322 ; DOl: https://doi.org/10.4000/jsa. 1322 


\title{
TEMAS RITUALES EN LA CERÁMICA «TIPO CÓDICE » DEL ESTILO MIXTECA-PUEBLA
}

\author{
Gilda HERNÁNDEZ SÁNCHEZ *
}

Aquí se presentan resultados de un estudio de la iconografía pintada en cerámica « tipo códice » del estilo Mixteca-Puebla, fechada para el Postclásico Tardío (12501521 d.C.), procedente de varios sitios arqueológicos en los estados de Puebla, Tlaxcala, Oaxaca y Veracruz, México. Esta iconografia es similar a la de los códices del Grupo Borgia y los mixtecos. Al parecer, los motivos pintados en mucha de esta cerámica formaban una pictografía que refería al uso ritual de las vasijas, pues hay grupos de motivos que ocurren en una misma vasija, o en varias, y que forman un tema iconográfico. Los temas más frecuentes parecen aludir a varias de las principales actividades rituales en Mesoamérica. Aquí se comentan el complejo de Banda Solar, el de Plegaria a los Difuntos, el de Ofrenda a la Tierra, y el de Humo y Oscuridad. [PAlabras Claves : cerámica " tipo códice », estilo Mixteca-Puebla, Cholula, iconografía, pictografía, códice, Grupo Borgia, códices mixtecos, ritual.]

Thèmes rituels sur la poterie du type "Codex" de style Mixteca-Puebla. Cet article présente les résultats d'une étude de l'iconographie peinte sur la poterie du type " codex » de style Mixteca-Puebla, datant de la période Postclassique récente (12501521 apr. J.-C.) et provenant de plusieurs sites des États de Puebla, Tlaxcala, Oaxaca et Veracruz au Mexique. Cette iconographie est similaire à celle des codex du Groupe Borgia et des codex mixtèques. Il apparaît que les motifs peints sur cette céramique composent une pictographie faisant référence à une utilisation rituelle de ces récipients. De plus, il existe des groupes de motifs figurant sur un ou plusieurs récipient(s) et constituant un thème iconographique spécifique. Les thèmes les plus fréquents renvoient à des activités rituelles importantes en Mésoamérique. Nous en commenterons quatre : le complexe de la bande du Soleil, la prière aux défunts, l'offrande pour la terre, enfin, celui de la fumée et de l'obscurité. [Mots clés : céramique de type " codex », style Mixteca-Puebla, Cholula, iconographie, pictographie, codex, Groupe Borgia, codex mixtèques, rituel.]

Ritual themes on "Codex-style " pottery of the Mixteca-Puebla tradition. This paper presents the results of a study of the iconography painted on « codex-style " pottery of the Mixteca-Puebla tradition, dating from the Late Postclassic period (A.D. 1250-

* Onderzoekschool CNWS Rijks Universiteit Leiden, Holanda [g.h.sanchez@let.leidenuniv.nl]. Journal de la Société des Américanistes, 2004, 90-2, pp. 7-34. O Société des Américanistes. 
1521), and found in several sites in the states of Puebla, Tlaxcala, Oaxaca and Veracruz, Mexico. This iconography is similar to that on the Borgia Group and Mixtec codices. It is suggested that the motifs painted on much of this ceramic formed a pictography referring to the ritual use of the vessels; there are groups of motifs depicted in one or several vessel(s) that formed a specific iconographical theme. The most frequent themes seem to refer to some of the main ritual activities in Mesoamerica. Four of them are commented in this paper : the complex of the Solar Band, of Prayer to the Deceased, of Offering to the Earth and of Smoke and Darkness. [KEY IVORDS : "codex-style » pottery, Mixteca-Puebla tradition, Cholula, iconography, pictography, codex, Borgia Group, Mixtec codices, ritual.]

Durante el Postclásico, Cholula (Puebla) fue un importante centro religioso y foco de peregrinaje regional, de tal magnitud que en 1581 su regidor Gabriel de Rojas (1985, p. 131) la comparó con Roma o la Meca. También era conocido que allí se producía una loza de vivo colorido y gran calidad (Díaz del Castillo 1938, I, p. 331 ; Torquemada 1969, I, p. 282). Seguramente debió tratarse de la que hoy en día se conoce como cerámica polícroma " tipo códice » del estilo MixtecaPuebla, que es una de las más elegantes y elaboradas de Mesoamérica. Ahora se sabe que ésta no sólo existió en Cholula, sino en otros sitios del valle poblanotlaxcalteca, en el estado de Oaxaca, en el centro del estado del Veracruz y, escasamente, en la ciudad de México, durante la última parte del Postclásico.

Esta cerámica se distingue por tener una decoración pintada al estilo de los códices y es por eso que se le llama « tipo códice » (Robertson 1961, p. 4). Eduard Seler $(1908$, p. 522) desde principios del siglo xx reconoció que los motivos plasmados en ella eran parte del corpus iconográfico de los códices del Grupo Borgia y los mixtecos. Además, Hermann Beyer (1969, p. 469), en su estudio de una vasija « tipo códice » de Cholula, señaló que la alta calidad de esta cerámica sugería un uso ceremonial. Ambas ideas siguen siendo retomadas en la literatura (p. ej., Chadwick 1971, p. 240 ; Contreras 1994b, p. 12 ; Lind 1967, 1994, pp. 87, 93 ; McCafferty 1994, p. 72 ; Müller 1970, 1978 ; Nicholson 1982, p. 243 ; Quiñones 1994 ; Ramsey 1975, 1982 ; Smith y Heath-Smith 1980, p. 33), aunque hasta ahora no se había hecho un análisis extensivo de la iconografía de estas vasijas.

El estudio que estamos realizando sobre esta iconografía se basa en una muestra grande de vasijas " tipo códice » y ambiciona interpretar su significado. Una hipótesis derivada del análisis en curso es que los motivos pintados en muchas de ellas no eran elementos copiados de los códices sólo para embellecerlas, sino que formaban una pictografía, con motivos estandarizados y organizados, que refería al uso ritual de las vasijas. Es decir, se han detectado grupos de motivos que ocurren juntos en una misma vasija, o en varias, y que forman un tema iconográfico específico. La mayoría de esos temas parece referir a conceptos básicos asociados con algunas de las principales actividades rituales en Meso- 
américa, por lo que es de proponer que aludían al uso de las vasijas. Aquí se comentarán cuatro de los temas iconográficos que mejor ejemplifican esta propuesta. Estos son el llamado complejo de Banda Solar; el de Plegaria a los Difuntos, el de Ofrenda a la Tierra, y el de Humo y Oscuridad. El que en las vasijas se hayan plasmado referencias a actividades rituales sugiere que formaban parte de su parafernalia, tanto en la ciudad religiosa de Cholula como en los otros sitios del centro de Mesoamérica donde se han encontrado.

Estas vasijas son una de las manifestaciones típicas del estilo Mixteca-Puebla, un estilo distintivo e iconografía compartida que durante el Postclásico se expresó en códices, cerámica y pintura mural (Nicholson 1966, 1982; Nicholson y Quiñones 1994 ; Sisson y Lilly 1994); siendo su más claro exponente el Codex Borgia. Los motivos pintados en ellas, que son dibujos de objetos y acciones, forman un sistema de imágenes conocido como pictografía (Boone 2000, pp. 31-32 ; Dibble 1971, p. 324). A muchos de estos motivos es posible asignarles una palabra o un significado específico gracias a la existencia de códices y fuentes coloniales tempranas que ilustran, con un estilo similar, objetos y actividades prehispánicas con su explicación. Por ejemplo, el Codex Mendoza (1992) muestra listas de motivos con glosas explicativas en náhuatl y español, y el Codex Magliabechi (1983) representa dioses y ceremonias acompañados de un texto descriptivo en español.

Gran parte de la información sobre rituales y religión en el Postclásico Tardío viene de la cuenca de México, mientras que datos similares para Puebla, Tlaxcala, Oaxaca y el centro de Veracruz son muy escasos. Sin embargo, es viable considerar la información de la cuenca para interpretar los motivos Mixteca-Puebla, pues en varias regiones del centro de Mesoamérica había para ese tiempo una tradición religiosa compartida (Nicholson 1971, p. 397). Además, este corpus iconográfico se utilizó en varias regiones por lo que sus motivos debieron tener significados similares.

\section{LA MUESTRA DE ESTUDIO}

El estudio se basa en una muestra de 405 vasijas ${ }^{2}$ « tipo códice », completas o en fragmentos lo suficientemente grandes como para ver su arreglo iconográfico $^{3}$. El $39.51 \%$ de ellas vienen del valle de Puebla-Tlaxcala (Figuras 1 y 2), principalmente de Cholula, Tizatlán y Ocotelulco. Estos dos últimos sitios eran ciudades importantes de Tlaxcala al momento de la conquista española (Carrasco 1971, p. 472 ; Gibson 1952, p. 11). Además, un $6.91 \%$ de la muestra viene de diferentes lugares en la Mixteca, la mayoría de la Mixteca Alta, y un $17.28 \%$ de los valles centrales de Oaxaca y otros sitios en el mismo estado. Un 14.81\% procede de varios lugares en el centro del estado de Veracruz, un $3.46 \%$ de la ciudad de México, y un $18.02 \%$ no tiene procedencia. Aunque se sabe de qué 


\begin{tabular}{|c|c|c|c|c|c|c|c|}
\hline \multicolumn{2}{|c|}{ Puebla-Tlaxcala } & \multicolumn{2}{|c|}{ Centro de Veracruz } & \multicolumn{2}{|l|}{ La Mixteca } & \multicolumn{2}{|c|}{ Valle de Oaxaca } \\
\hline Cholula & 99 & Cerro Montoso & 15 & Nochixtlán & 7 & Zaachila & 25 \\
\hline Ocotelulco & 21 & Piedras Negras & 11 & Chachoapa & 5 & Huitzo & 15 \\
\hline Tizatlán & 11 & Zempoala & 8 & Coixtlahuaca & 2 & Yagul & 3 \\
\hline Huejotzingo & 4 & Río Blanco & 3 & Tututepec & 2 & Monte Albán & 2 \\
\hline Acatzingo & 2 & Los Otates & 2 & Apoala & 1 & Tlacolula & 1 \\
\hline Chiantzingo & 1 & Cotaxtla & 1 & Sn. P. Topiltepec & 1 & Valle de Etla & 1 \\
\hline Tianguismanalco & 1 & Quauhtochco & 1 & Tilantongo & 1 & Zimatlán & 1 \\
\hline Tepeji el Viejo & 1 & I. de Sacrificios & 1 & Zahuatlán & 1 & Total & 48 \\
\hline Edo. de Puebla & 2 & Edo. de Veracruz & 2 & La Mixteca & 7 & & \\
\hline Edo. de Tlaxcala & 2 & Veracruz p.e.* & 16 & La Mixteca p.e.* & 1 & & \\
\hline Cholula p.e.* & 15 & Total & 60 & Total & 28 & & \\
\hline \multirow[t]{7}{*}{ Total } & 159 & & & & & \multicolumn{2}{|c|}{ Otros en Oaxaca } \\
\hline & & \multicolumn{2}{|c|}{ Cuenca de México } & & & Ayotzintepec & 9 \\
\hline & & Escalerillas & 6 & & & Cuicatlán & 2 \\
\hline & & El Volador & 4 & & & Sola de la Vega & 1 \\
\hline & & Templo Mayor & 4 & & & Teojomulco & 1 \\
\hline & & Huexotla & 1 & & & Edo. de Oaxaca & 9 \\
\hline & & Total & 15 & & & Total & 22 \\
\hline
\end{tabular}

* p.e. = por estilo asignado a esa región o sitio

FIG. 1 - Procedencia y frecuencia de las vasijas de la muestra.

sitios provienen la mayoría de estas vasijas, en muy pocos casos se tiene información sobre su contexto arqueológico específico.

Las formas de vasija registradas en la muestra se representan en la Figura 3. En general, las vasijas están pintadas con la misma técnica y tienen una iconografía similar aunque sí hay diferencias regionales. Michael Lind (1994, pp. 92 97), en un estudio comparativo entre las vasijas « tipo códice » de Cholula y las de la región de Oaxaca, demostró que hay algunos motivos que sólo aparecen en una de ambas regiones, otros que son más frecuentes en una región, y otros que ocurren en ambas.

Las vasijas «tipo códice» son más elaboradas que las demás cerámicas contemporáneas en cada sitio. También son escasas ; por ejemplo, en Cholula y en la Mixteca representan entre el 2 y el $5 \%$ de los artefactos cerámicos recuperados de contextos domésticos (Lind 1994, p. 86). En cada región son las únicas que tienen iconografía del estilo Mixteca-Puebla pintada con alta calidad, y con frecuencia los motivos representan temas religiosos. Además, algunas de sus formas, como el sahumador y el incensario, sugieren un claro uso ceremonial. Todo esto apunta a que por lo menos algunas de las vasijas eran reservadas para actividades rituales. 


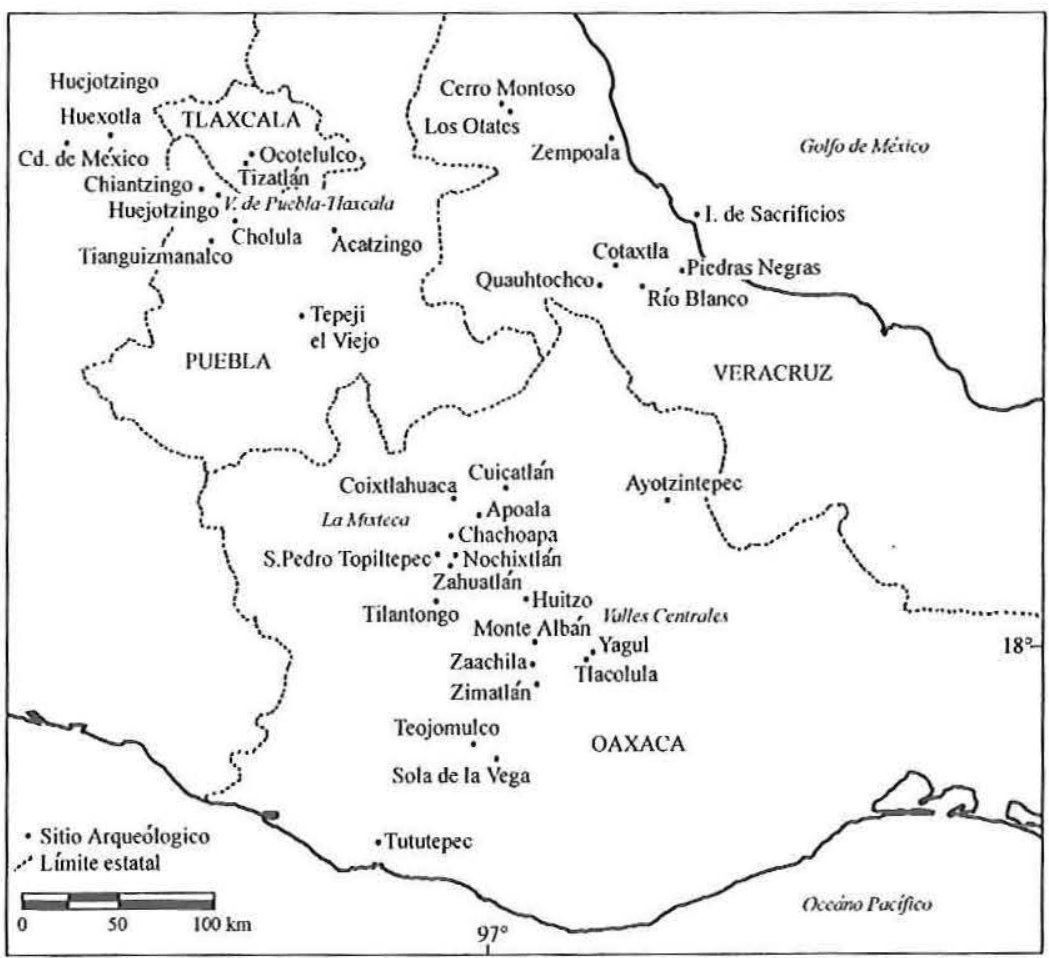

FIG. 2 - Ubicación de los sitios arqueológicos de donde provienen las vasijas de la muestra (mapa modificado de World Länderkarte 1998).

$\mathrm{Al}$ considerar en conjunto la muestra, se distinguen varios grupos de vasijas de acuerdo a su iconografía. Cada grupo presenta un complejo particular de motivos, que suelen ocurrir juntos en una misma vasija y muestran un arreglo estándar. Esos motivos están generalmente organizados en bandas alrededor de la vasija. Estas bandas junto con motivos independientes en el fondo o cuerpo de las vasijas parecen formar temas iconográficos específicos. Algunos de esos temas se asocian a ciertas formas de vasija, e incluso a ciertas regiones geográficas. Aquí se ofrece una interpretación de cuatro de los temas iconográficos que mejor ejemplifican la propuesta de que la iconografía refería al uso ceremonial de las vasijas. Estos son el complejo de Banda Solar, el de Plegaria a los Difuntos, el de Ofrenda a la Tierra, y el de Humo y Oscuridad. Es de remarcar que la pictografía Mixteca-Puebla es muy compleja y variada. Un mismo motivo en contextos diferentes puede significar cosas distintas, a la vez que un mismo motivo se puede representar de diferentes formas (Jansen 1982, p. 84). Además, como es de 


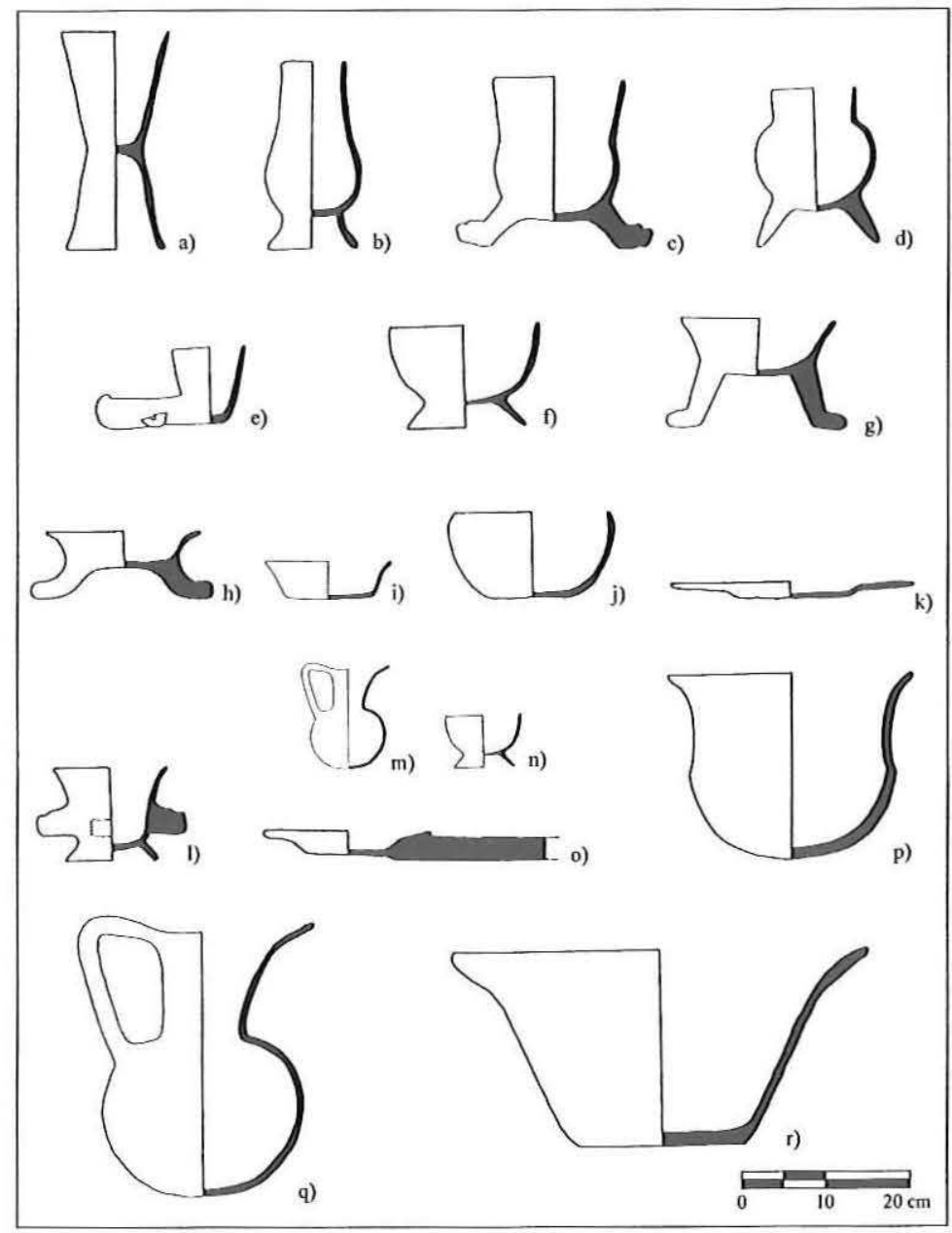

Fig. 3 - Formas de vasija en la muestra : a y b) vaso bicónico ; c) vaso trípode ; d) ollita trípode ; e) vaso de garra ; f) copa ; g h h) cajete trípode evertido ; i) cajete evertido ; j) cajete convergente ; k) plato ; l) incensario ; m) olla miniatura ;n) copa miniatura ;o) sahumador ; p) cajete grande de silueta compuesta ; q) olla ; r) apaxtle.

carácter ideográfico pues tiene que ver con las cualidades o ideas asociadas con los objetos representados (Dibble 1971, p. 324), y un mismo conjunto de motivos suele tener varios niveles de significado. Por consiguiente bien puede haber lecturas distintas a las que aquí se ofrecen. 


\section{COMPLEJO DE BANDA SOLAR}

Éste es el complejo más abundante de la muestra ; incluye 46 vasijas que pueden ser platos $(45.65 \%)$, cajetes trípodes evertidos $(28.26 \%)$, apaxtles $(15.22 \%)$, copas $(4.35 \%)$, cajetes convergentes $(4.35 \%)$ u ollitas trípodes $(2.17 \%)$. La mayoría, el $80.4 \%$, viene de Cholula, Tizatlán y Ocotelulco. Se identifican por tener cerca del borde una banda anaranjada con líneas verticales y ganchos rojos (figuras 4 y 5). Sobre ella se pintan una serie de motivos ; los más comunes son espinas de maguey y punzones de hueso. Esta banda parece representar al sol porque el patrón de líneas verticales y ganchos rojos ocurre en esculturas que simbolizan al disco solar, como la Piedra del Sol (Matos Moctezuma 1988, Foto 8) o la Piedra de Tizoc (Townsend 1992, figs. 49-50). También en los códices el sol suele pintarse con esta banda (Borbonicus 1991, p. 14 ; Cospi 1994 , p. 12). Además, la que aquí se llamará banda solar ocurre alrededor de bordes de vasija de boca redonda por lo que a la vista conforma un disco, como el sol.

En Mesoamérica el sol es el principio de vida, es la energía que nutre a todos los seres vivientes. Es resplandeciente, alumbra y calienta (Sahagún 1992, VII, Cap. 1, p. 431). Es el que todo lo ve, el testigo de nuestras acciones (Anders y Jansen 1993, p. 134). También parece simbolizar lo sagrado, lo de los dioses, pues en el Codex Mendoza hay varios sitios cuyo nombre lleva la partícula teotl, dios, o teoyotl, cosa sagrada, que se representan con un sol (Berdan y Anawalt 1992, p. 208). Por ejemplo, Teoaçinco (Mendoza 1992, p. 16r), « en la pequeña agua sagrada ", se indica con un medio disco solar con rayos y piedras preciosas, una cuenca de agua y la porción inferior de un hombre. También Teoçiocan (ibid., p. 49r) se pinta con un medio disco solar con mazorcas; Teonochtitlan (ibid., p. 42r), con el medio sol y un nopal con tuna, y Teopantlan (ibid., p. 42r) con el medio sol y un templo. Así en las vasijas la banda solar puede aludir al sol, a la energía vital y a lo de los dioses.

Sobre la banda solar usualmente se pintan pares de espinas de maguey que se alternan con pares de punzones de hueso, o pares de espinas alternadas con cabezas de faisán. Algunas veces, las espinas y huesos se combinan con otros motivos como mazorcas de maíz, piedras preciosas o rayos solares. Las espinas y los punzones de hueso eran los típicos instrumentos de autosacrificio. Por ello en los códices se representan con frecuencia para simbolizar nociones asociadas a esta actividad ritual, como devoción, sumisión, penitencia y la ofrenda de uno mismo; lo que se puede resumir dentro del concepto de purificación ritual (Jansen 1998, 144). La combinación de huesos y espinas debió ser una referencia común a ese concepto. En códices del centro de Mesoamérica ambos suelen aparecer juntos (p. ej., Borbonicus 1991, p. 5 ; Borgia 1993, pp. 18, 19, 22, 23 ; Fejérváry-Mayer 1994, pp. 11, 14, 32 ; Nuttall 1992a, p. 21), lo que sugiere que formaban una metáfora conocida. 


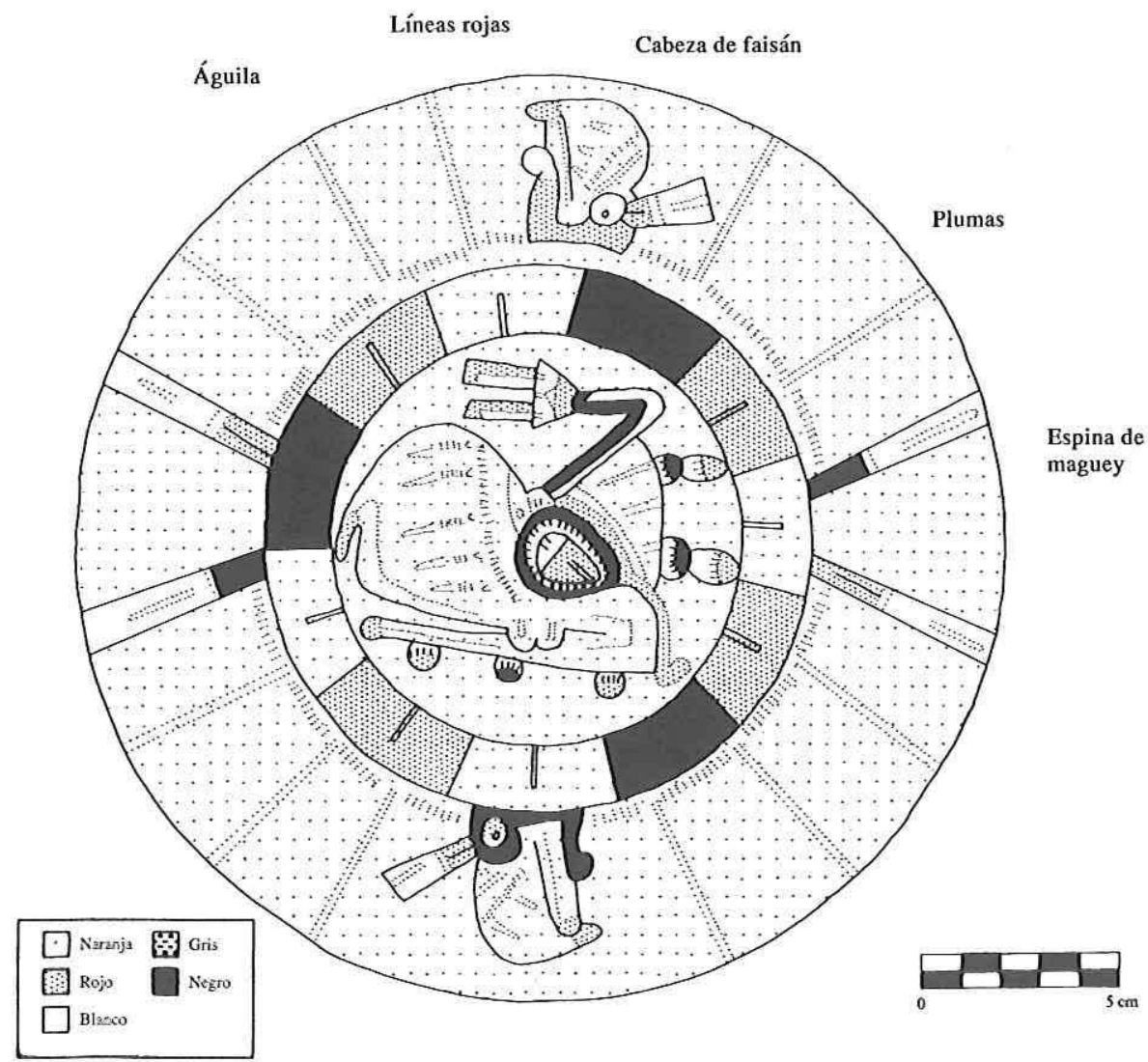

FIg. 4 - Plato con iconografía del complejo de Banda Solar atribuido a Cholula. Depositado en el centro INAH de Puebla (clave 10-497092).

La cabeza de faisán se considera un emblema de la riqueza y lo precioso, y de Xochipilli el patrón de la nobleza (Seler 1963, I, pp. 72, 103). La piedra preciosa indica preciosidad y cosas valiosas (Nicholson y Quiñones 1983, p. 37), y el maíz suele ser símbolo de abundancia de víveres y riqueza (Anders y Jansen 1993, p. 120). Estos tres motivos al alternarse con espinas o huesos en la banda solar parecen añadirle al concepto de purificación ritual los calificativos de nobleza, preciosidad y abundancia. Los rayos solares que en ocasiones se pintan en esta banda debieron reforzar la alusión al disco solar.

Junto con la banda solar; otros elementos de este complejo de motivos son una banda de plumas de colores y/o una banda de xicalcoliuhqui o grecas escalonadas. Las plumas, por lo general, son un típico indicador de preciosidad y 


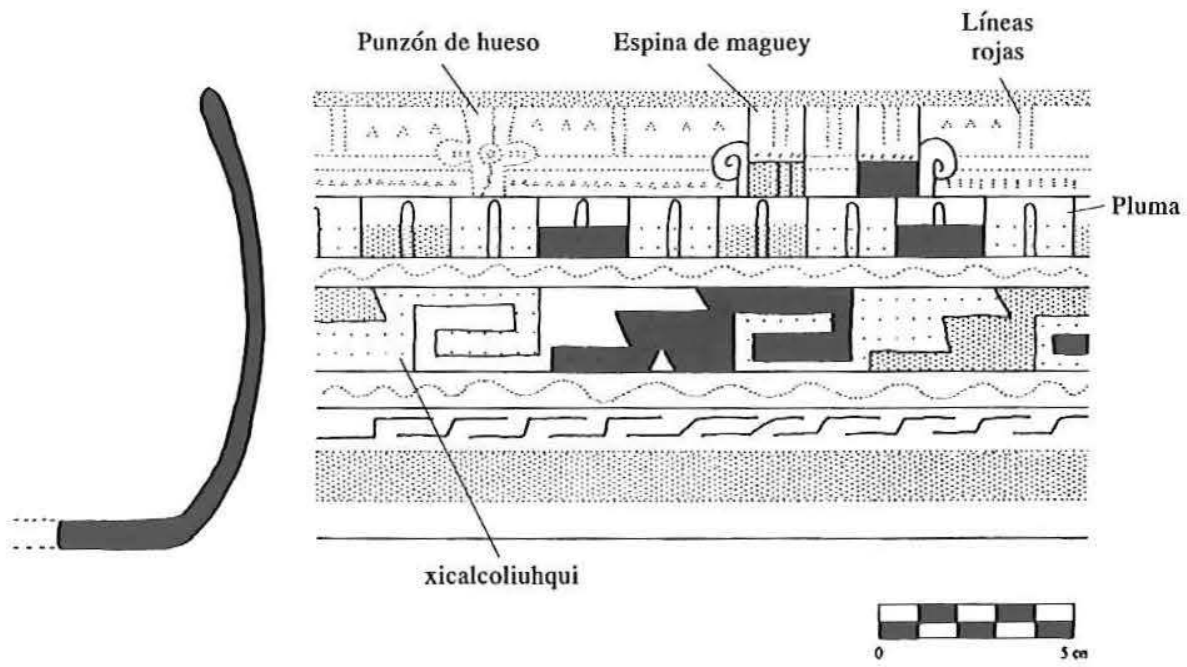

FIG. 5 - Cajete convergente de Cholula con iconografía del complejo de Banda Solar. Depositado en el laboratorio de Arqueología de la Universidad de Las Américas-Puebla. Es la misma leyenda de color que en la Figura 4.

elegancia en Mesoamérica (Aguilera 1978, p. 18). En los códices mixtecos, un tablero de grecas escalonadas significa pueblo, que a su vez connota lo noble y la gente de linaje (Jansen y Pérez Jiménez 2000, p. 14). En el área maya, xicalcoliuhqui y grecas escalonadas parecen asociarse con nobleza y linajes importantes (Sharp 1981, p. 7). Entonces es factible que en las vasijas también refieran a nobleza. Así, estas bandas de plumas y/o xicalcoliuhqui o grecas escalonadas junto con la banda que representa al sol pueden interpretarse como purificación ritual, preciosidad y nobleza en relación con el sol, con la energía que da vida, con lo de los dioses.

Además, en el fondo de platos y cajetes trípodes evertidos se pintó un motivo, grande y visible, sobre un fondo color naranja. Los motivos más frecuentes son cabezas en perfil de águila y de serpiente y ofrendas de maíz ; aunque también hay cabezas en perfil de mariposa, ofrendas de maiz con garra, jaguares de cuerpo entero, una joya de caracol, y las imágenes de Xipe y Xochiquetzal (Figura 6). El motivo más abundante es el águila, que es representante del sol y un guerrero celeste (Beyer 1965, p. 139 ; Seler 1963, I, p. 126). También uno de los nombres del sol era águila ascendente (Sahagún 1997, p. 124). En las vasijas la mayoría tiene en el pico una mancha de sangre que puede referir a que una de sus funciones era nutrir al sol con sangre preciosa (Seler 1963, I, p. 126). Así, es posible que las águilas reforzaban el concepto de purificación en relación con el sol. 


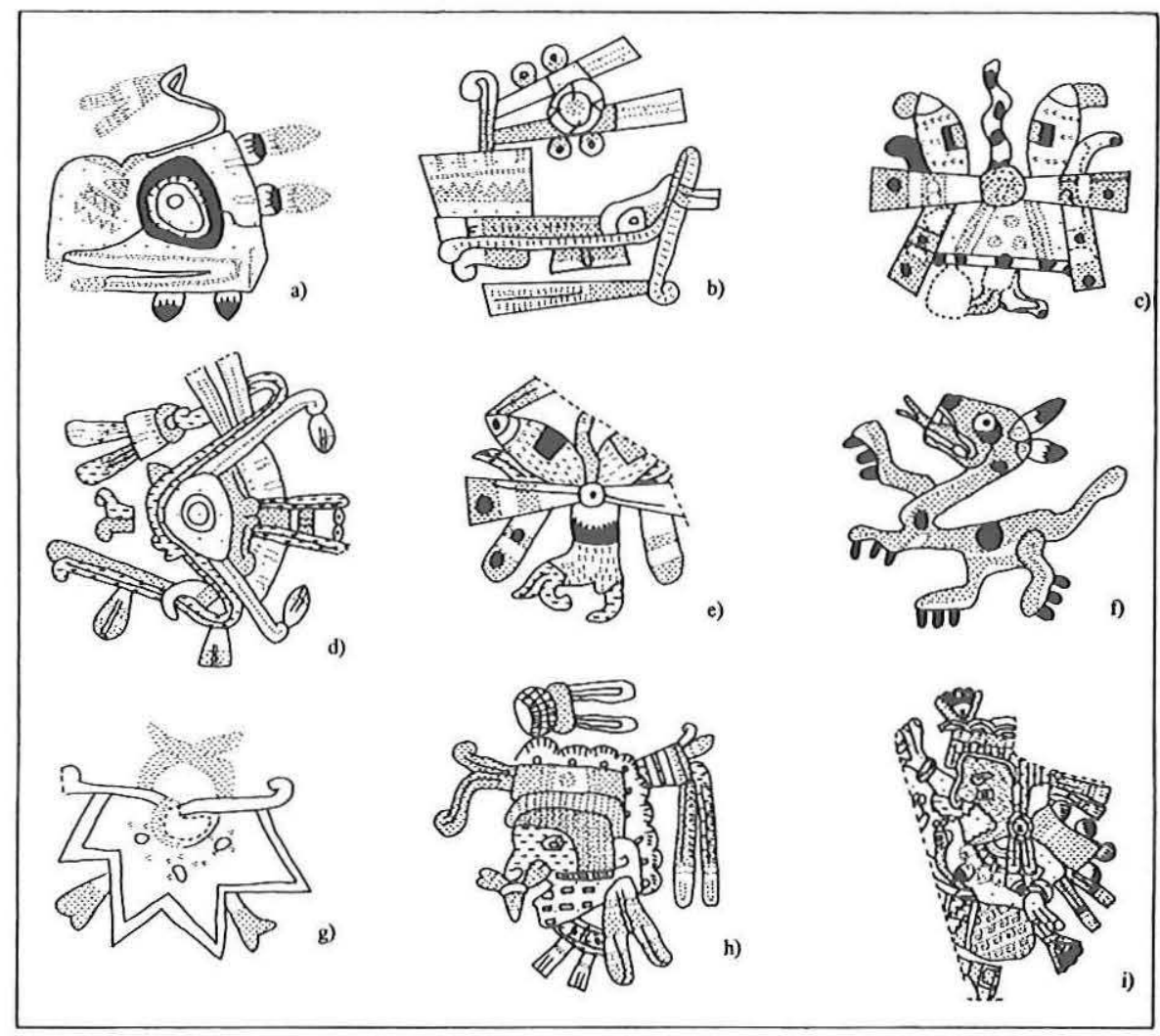

FIG. 6 - Signos en el fondo de vasijas del complejo de Banda Solar : a) águila, b) serpiente, c) ofrenda de maiz, d) mariposa, e) ofrenda de maiz con garra, f) jaguar, g) joya de caracol, h) Xipe, i) Xochiquetzal. Es la misma leyenda de color que en la Figura 4.

Los otros motivos más bien parecen referir al destinatario de esa purificación, de esa ofrenda y devoción. Por ejemplo, el motivo de ofrenda de maíz puede representar las ofrendas de mazorcas, papeles y hule que se hacían a Cinteotl y Chicomecoatl (Sahagún 1992, II, Cap. 23, p. 106). La ofrenda de maíz con garra, siguiendo a Nicholson (1994, pp. 109-113), es la síntesis de un motivo más complejo que ocurre en el Codex Borgia (1993, pp. 4, 6), el Vaticamus B(1993, p. 4) y el Cospi $(1994$, pp. 2, 4), que simboliza a deidades de la tierra y la fertilidad como Cinteotl, Chantico y Cihuacoatl. Así, estos motivos sugieren que la vasija se dirigía a los dioses de la tierra y la fertilidad.

Otro de los motivos, el jaguar, es el animal bravo que simboliza la valentía de los jóvenes guerreros (Anders, Jansen y Van der Loo 1994, p. 246). También se relaciona con la noche, la oscuridad y la tierra (Seler 1908, p. 524), y puede 
significar el peligro y la actividad de los nahuales (Anders y Jansen 1993, p. 130). Una posibilidad es que el motivo indicaba que la purificación ritual se relacionaba con los guerreros valientes y con la conjura de peligros. La serpiente, que lleva plumas en los belfos, puede aludir al dios Quetzalcoatl, representado como serpiente emplumada, y quizá también a un poderoso nahual o a la experiencia nahualística misma (Jansen 1997, pp. 34-35). En las vasijas pudo indicar que la purificación se dirigía a Quetzalcoatl y/o a un nahual poderoso.

En varias vasijas hay una joya de caracol, ehecailacozcatl en náhuatl, que es un adorno típico de Quetzalcoatl en los códices del Grupo Borgia (Seler 1963, I, p. 70), y debió simbolizarlo. Otra vasija tiene el rostro de Xipe y en otra se plasmó a Xochiquetzal. Una posibilidad es que en cada una de estas vasijas la purificación ritual se dirigía al dios representado en su fondo.

En breve, la iconografía de estas vasijas parece referir a la purificación ritual, a la nobleza y a la preciosidad en relación con el sol, con la fuente de vida y con lo de los dioses. En algunas vasijas se añade que el destinario de esa purificación, que involucra piedad, devoción y ofrenda, eran los dioses de la tierra y la fertilidad, Quetzalcoatl, Itzpapalotl o Xipe. En otras parece referirse a los guerreros valientes o los nahuales poderosos. Esto sugiere que las vasijas del complejo de Banda Solar eran parte en varias ceremonias relacionadas con el sol, por ejemplo las ligadas a la fertilidad agrícola o a los guerreros ; quizá como contenedores de ofrendas pues la noción de purificación ritual representada en ellas sugiere este tipo de actividad. La forma de las vasijas - plato, cajete evertido o apaxtle - bien pudo ser útil para ese propósito. Esto sugiere que la iconografía refería al uso ritual de las vasijas.

\section{COMPLEJO DE PLEGARIA A LOS DIFUNTOS}

Aquí se agrupan 17 vasijas del valle de Puebla-Tlaxcala y Veracruz. La forma más frecuente es el vaso bicónico es decir con pedestal alto $(70.59 \%)$, aunque también hay dos sahumadores, un vaso, un cajete trípode evertido y una copa. Se distinguen por tener cerca del borde una banda de franjas y líneas verticales negras sobre blanco (Figura 7). Este motivo parece ligarse en algunos contextos a Tezcatlipoca, pues en el Codex Magliabechi (1983, p. 33) se observa un personaje sentado en un banco o altar con el mismo patrón de franjas, y el texto asociado dice que era el ritual de Toxcatl, dedicado a Tezcatlipoca (Figura 8). También en el Borgia (p. ej., 1993, pp. 15, 17, 21, 69), Tezcatlipoca - mas no otra deidad - aparece en la mayoría de los casos con un ceñidor que en las puntas tiene este motivo ${ }^{4}$ (Figura 9). Sin embargo, aunque esa banda parece relacionarse a Tezcatlipoca, quizá no lo simboliza directamente, pues él tiene toda una serie de atavíos diagnósticos que son los que suelen usarse para representarlo. Más bien, la banda indica alguna de sus cualidades o atributos. Una posibilidad es que 


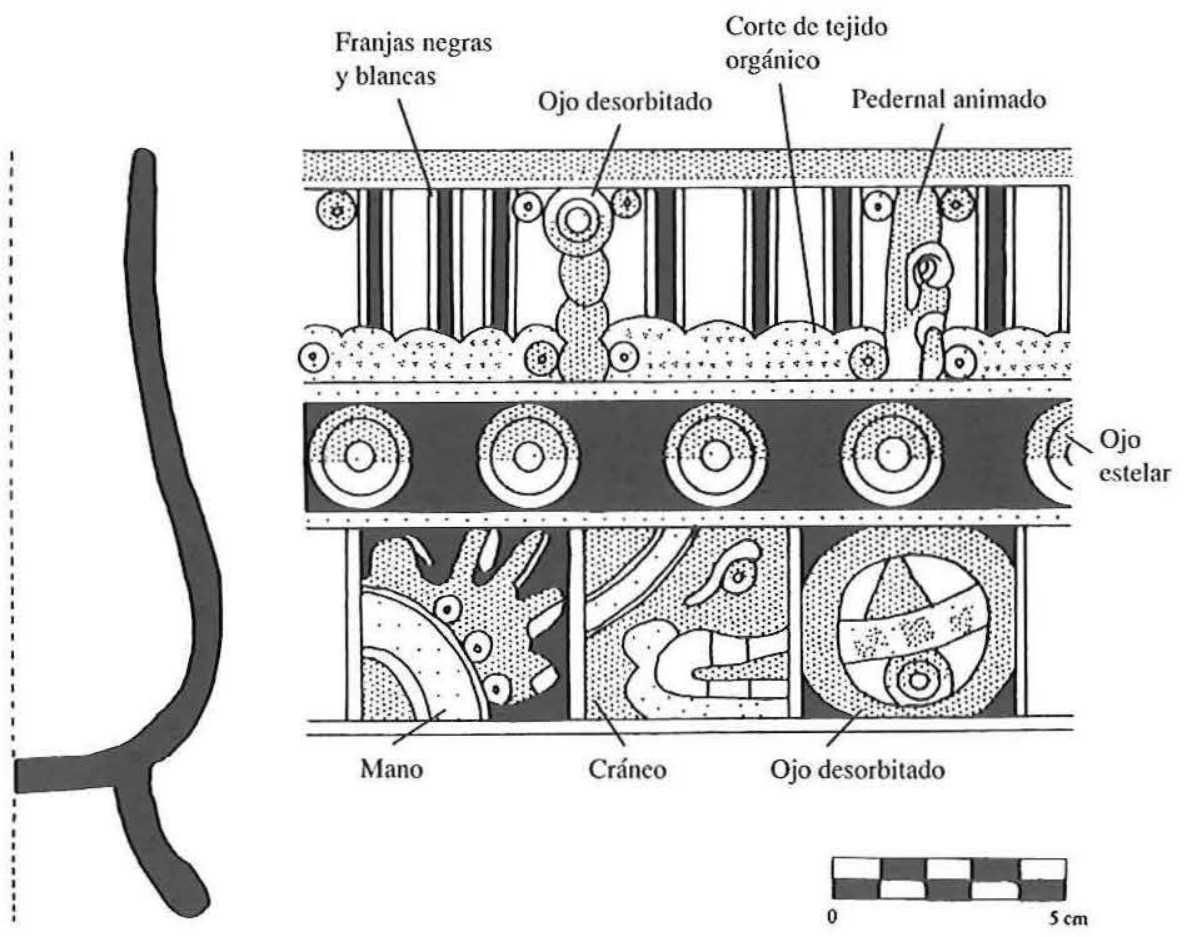

Fig. 7 - Vaso de Ocotelulco con iconografia del complejo de Plegaria a los Difuntos. Depositado en el centro INAH de Tlaxcala (clave 10-356269). Es la misma leyenda de color que en la Figura 4.

signifique oscuridad o negrura, una de las asociaciones de Tezcatlipoca, pues en el Codex Mendoza (1992, pp. 42v, 43r) hay mantas con este patrón, que en el paralelo de la Matrícula de Tributos se etiquetan como tlilpapatlavac, «capa negra ancha » en náhuatl (Berdan y Anawalt 1997, p. 104). Así, esta banda pudo indicar oscuridad ; un tipo de oscuridad que en algunos contextos se relacionaba con Tezcatlipoca.

Sobre esa banda, se pintan dos o tres motivos alternados que pueden ser espinas de maguey, ojos desorbitados, pedernales animados, hígados o un adorno de plumas. Las espinas y los pedernales son típicos instrumentos de sacrificio y por tanto pueden referir a purificación ritual, penitencia y devoción. El hígado se consideraba un órgano importante que producía uno de los fluidos vitales del cuerpo (López Austin 1996, p. 262). Además, los pedernales, al igual que los ojos desorbitados y los hígados, eran parte de la iconografía de los dioses de la muerte y el inframundo (veánse p. ej., Borgia 1993, pp. 7, 50, 52, 56, 73 ; Cospi 1994, p. 13 ; Magliabechi 1983, p. 76r ; Nuttall 1992, p. 84). Todos estos motivos junto 


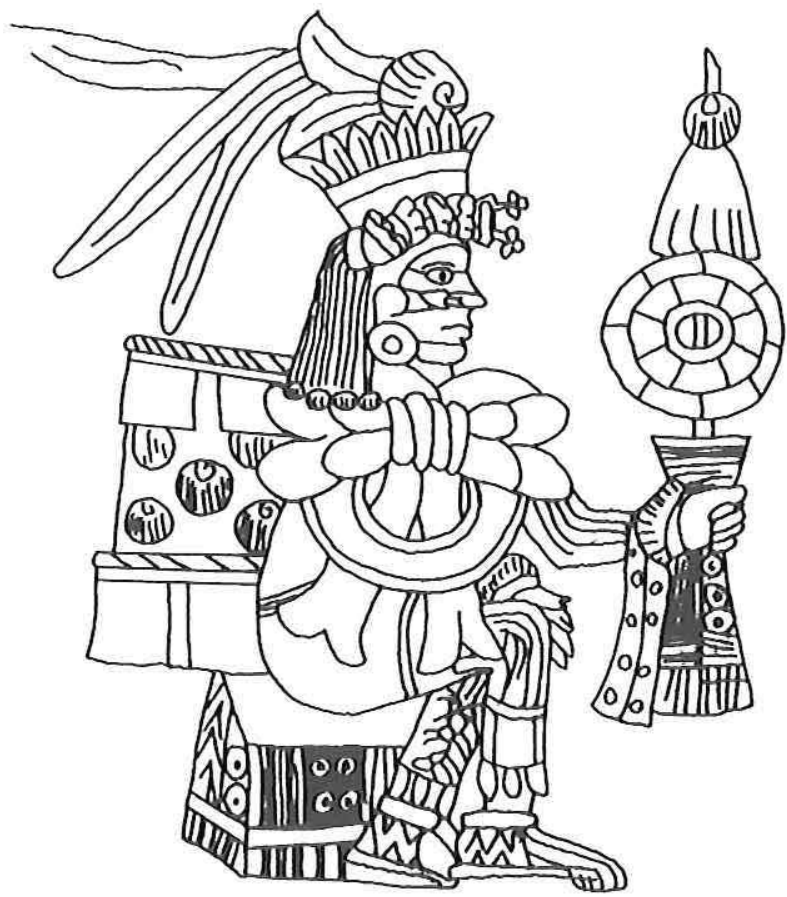

FIG. 8 - Personaje con atuendo de Tezcatlipoca en el Magliabechi. El banco en el que está sentado lleva el patrón de franjas negras sobre blanco similar al de las vasijas del complejo de Plegaria a los Difuntos (basado en Codex Magliabechi 1983, p. 33).

con la banda de franjas negras sobre blanco pueden interpretarse como oscuridad en relación con los dioses de la muerte y el inframundo.

Debajo, con frecuencia hay otra banda que es más delgada, de color naranja con puntos rojos y suele tener bordes ondulados. Ésta se asemeja al corte o herida que muestra la piel seccionada en los códices (Aguilera 1988, p. 69 ; p. ej., Borgia 1993, pp. 31-32). Y como tal es parte de la iconografía de los dioses de la muerte y el inframundo (p. ej., Borgia 1993, pp. 50, 52, 73). La siguiente banda es negra o gris con rayas horizontales y encima lleva ojos estelares que simbolizan la oscuridad, la noche y el trance (Anders y Jansen 1993, p. 229 ; Jansen 1998, p. 294). Esta banda también parece representar los cabellos oscuros con ojos estelares de los dioses de la muerte como se pintan en el Borgia (p. ej., 1993, pp. 13, 23, 50). Así, esta banda pudo referir a la noche y el trance, y a la vez a los dioses de la muerte.

Lo oscuro y la noche representan lo misterioso ; es la atmósfera en la que están los dioses y en la que se dan los rituales de trance para contactarlos (Anders, 


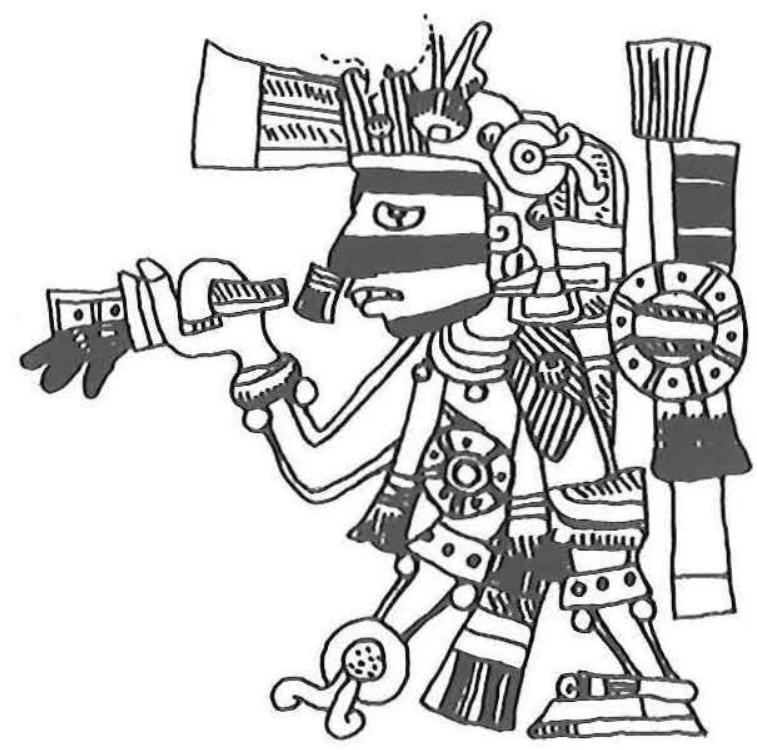

Fig. 9-Representación de Tezcatlipoca que en las puntas del maxtlatl lleva una banda de franjas negras sobre blanco similar a la de las vasijas del complejo de Plegaria a los Difuntos (basado en Codex Borgia 1993, p. 21).

Jansen y Reyes García 1993, p. 188 ; Jansen 1997, pp. 16, 26). En el Codex Borgia (1993) hay varias escenas en las que se ve cómo ese ambiente misterioso de los dioses y del trance es representado con motivos de oscuridad y ojos estelares. Por ejemplo, en la página 36 hay un envoltorio sagrado rodeado de oscuridad y misterio ; de él sale una banda negra, como una serpiente de visión oscura y con ojos estelares, en la que va en trance el sacerdote de Xolotl (Anders, Jansen y Reyes García 1993, p. 214). En las vasijas de este grupo la oscuridad también puede referir al ambiente misterioso de los dioses y del trance. $\mathrm{Y}$ a la vez, al lugar a donde van los difuntos, que era el "lugar oscurísimo que no tiene luz, ni ventanas... » (Sahagún 1992, III, Ap. Cap. 1, p. 205).

En la banda que suele ser la más ancha de estas vasijas hay una serie de motivos que son cráneo, mano, corazón, hígado y un elemento complejo que parece ser un ojo desorbitado (Figura 10). Éste es un motivo difícil de entender ; se trata de un disco que al centro lleva un ojo estelar con una prolongación alargada roja, aunque el ojo y esa prolongación están separados por una banda naranja. Se ha interpretado como un escudo (Caso 1927, pp. 14-15; Pohl 1998, p. 191), un gran chalchihuite (Solís 1995, p. 32), o un espejo (Peperstraete 2002, pp. 23-24). En mi opinión parece ser una representación elaborada de un ojo desorbitado ; quizá con un significado más complejo que ahora no es claro. Esto 


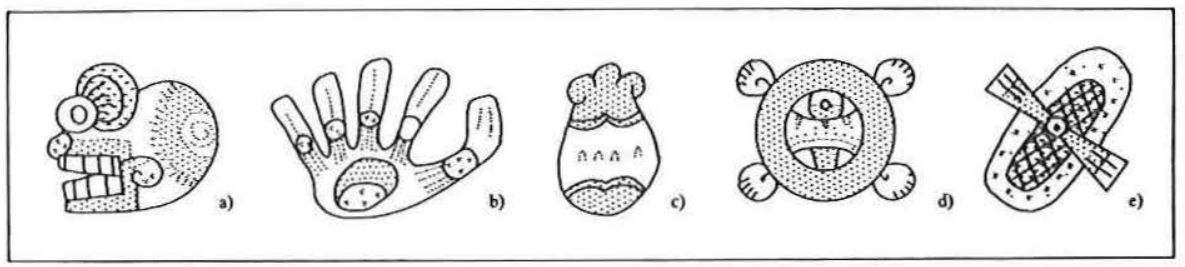

FIG. 10 - Signos en la banda más ancha de las vasijas del complejo de Plegaria a los Difuntos : a) cráneo, b) mano, c) corazón, d) ojo desorbitado, e) órgano interno. Es la misma leyenda de color que en la Figura 4.

correspondería bien con los otros motivos de la banda, pues ojos desorbitados junto con cráneo, mano, corazón e hígado son típicos de la iconografía de los dioses de la muerte y del inframundo (p. ej., Borgia 1993, pp. 7, 50, 52, 56, 73 ; Cospi 1994, p. 13 ; Magliabechi 1983, p. 76r ; Nuttall 1992, p. 84). Así, esta banda pudo referir a los dioses de la muerte y el inframundo. En una misma vasija suelen aparecer en la banda dos, tres o hasta cuatro de esos motivos alternados, que por norma están sobre un fondo oscuro que los relaciona con la oscuridad y la noche.

Sahagún (1992, II, Cap. 24, p. 109) menciona que en el ritual de Toxcatl, dedicado a Tezcatlipoca, la imagen de Huitzilopochtli llevaba una manta « [...] en la cual estaban labrados los huesos y miembros de una persona despedazada ; a esta manta, labrada de esta manera, llamaban tlacuacuallo ». Garibay (1992, p. 953) traduce esta palabra náhuatl como « manjares ». Al parecer esto tenía que ver con la idea de que los dioses del inframundo se alimentaban de pies, manos y pus (Sahagún 1997, p. 177). Esa imagen también vestía un chalequillo con " miembros humanos despedazados: todo él está pintado de cráneos, orejas, corazones, intestinos, tórax, tetas, manos, pies » (Sahagún 1992, XII, Cap. 19, p. 778). Capas similares adornaban las imágenes de Tezcatlipoca según Durán (1980, p. 106), y también eran usadas por los señores recién elegidos en su penitencia inicial (Sahagún 1992, VIII, Cap. 18, p. 473). Así, es posible que Tezcatlipoca y los nuevos señores usaban mantas que aludían a los difuntos ${ }^{5}$. Aquí Guilhem Olivier (2003, pp. 79-81) argumenta convincentemente que esas mantas portadas por los nuevos reyes eran las que cubrían los envoltorios sagrados, tlaquimilolli, de Tezcatlipoca y Huitzilopochtli.

Al parecer este particular complejo de motivos que refería a los dioses de la muerte se asociaba en algunos contextos a Tezcatlipoca. Como arriba se menciona, las imágenes de Tezcatlipoca vestían capas con esos motivos. También, en los murales de Tizatlán (Caso 1927) y de Ocotelulco (Contreras 1994b) se pintaron bandas con cráneos, manos, corazones y el posible ojo desorbitado en asociación con representaciones de Tezcatlipoca. Incluso, en Ocotelulco el patrón de motivos es muy similar al de estas vasijas. El altar tiene en la parte inferior una 
banda de franjas negras sobre blanco con espinas de maguey; este patrón también es el fondo sobre el cual descienden varias serpientes. Además, hay una banda de ojos estelares sobre fondo oscuro ; y en el banco a los lados del altar ocurre una banda con cráneos, corazones, manos y los posibles ojos desorbitados sobre un fondo oscuro. Y en la parte frontal del altar aparece el rostro de Tezcatlipoca saliendo de un pedernal (Contreras 1994a) ${ }^{6}$. Además, un cajete trípode de este complejo que viene de Ocotelulco muestra en el fondo la imagen de un viejo sacerdote Tezcatlipoca en trance (Jansen 1998, p. 287), en vez de tener los motivos de partes del cuerpo como en las otras vasijas. Este caso excepcional apoya la idea de que la referencia a los difuntos en estas vasijas se vinculaba a Tezcatlipoca.

En breve, la iconografía en conjunto parece referir a los dioses de la muerte y el inframundo, y por extensión a los difuntos y a los antepasados, en un contexto de oscuridad y misterio. En Mesoamérica prehispánica el culto a la muerte parece dirigirse a antepasados específicos o a difuntos particulares, más que ser una veneración a la muerte como concepto abstracto y no personificado. A través de toda una serie de rituales complejos los muertos no eran olvidados ; lo que es más, se mantenían activas líneas de comunicación entre ellos y los vivos (McAnany 1995, p. 1). Incluso en la cuenca de México había dos veintenas dedicadas a ellos, Miccailhuitontli, la fiesta pequeña de los muertos, y Xocotl Huetzi, la fiesta grande de los muertos (Durán 1967, I, pp. 269-273). Así la iconografía de estas vasijas pudo servir para elevar una plegaria a los difuntos, más que a la muerte en general (M. Jansen, comunicación personal 2004). Esa plegaria se rodeaba de un ambiente de oscuridad, misterio y trance, pues así era el lugar a donde iban los que morían, el lugar del más allá y de los dioses, y también era el contexto en que se daban los rituales para contactarlos.

Es posible que en esa plegaria se involucraba a Tezcatlipoca ; él era el dios todopoderoso (Nicholson 1971, p. 412). Su característica esencial era el carácter cambiante : « daba riquezas, prosperidades y fama, y fortaleza y señoríos, dignidades y honras, y las quitaba cuando se le antojaba » (Sahagún 1992, I, Cap. 4, p. 32), lo que promovía su poder completo y la dependencia de los humanos en él (Olivier 2003, p. 16). Por eso se le hacían muchas ofrendas, y quizá también por ello se le involucraba en el culto a los difuntos. Así, estas vasijas pudieron ser parte de la parafernalia de rituales para los difuntos. La mayoría de las formas son vasos o copas bicónicas, formas diseñadas para contener líquidos, por lo que es factible que una parte de ese ceremonial incluyera alguna bebida en las vasijas de este complejo. No hay evidencia para suponer que eran una vajilla funeraria, pues en la muestra ninguna de las vasijas viene de entierros, aunque sí es de aclarar que sólo en un caso se tiene información específica de la procedencia ${ }^{7}$. 


\section{COMPLEJO DE OFRENDA A LA TIERRA}

Este grupo incluye seis vasijas que vienen del valle de Puebla-Tlaxcala ; cuatro son vasos, una es un incensario y otra un sahumador. Se distinguen por tener cerca del borde una banda delgada anaranjada con plumas de águila (Figura 11). Debajo, hay una banda más ancha que es anaranjada y lleva el patrón de rombos y ganchos con que se representa la tierra seca en los códices del Grupo Borgia (p. ej., Borgia 1993, pp. 19, 27 ; Cospi 1994, p. 11). En esos ejemplos de los códices, en la banda de tierra seca y en sus bordes hay plumas de águila ; lo mismo ocurre en las vasijas. Así, parece que esas plumas complementan el concepto de tierra seca, pues siendo el águila representante del sol, sus plumas quizá refuerzan la noción de que el sol seca y daña la tierra. Además, sobre la banda de tierra pueden estar pintados un aztaxelli, el nombre náhuatl de un adorno guerrero con plumas de garza ; una bandera y escudo blancos que son típicos de la iconografía del sacrificio ; un hacha que puede referir a castigo, o un par de volutas de humo. En conjunto, estos motivos parecen referir a los guerreros, al sacrificio y al castigo, por lo que una lectura sería que la tierra estaba castigada y que se requería piedad y ofrenda de sacrificios, y valentía como la de los guerreros.

En los vasos de esta categoría se pintó igualmente una banda ancha con franjas verticales rojas sobre fondo blanco, y encima un gran ojo estelar. El patrón de franjas rojas sobre blanco es similar a la pintura corporal de Mixcoatl y Tlahuizcalpantecuhtli (Anders y Jansen 1993, p. 209 ; Seler 1963, I, p. 191). También es igual a la de los individuos destinados al sacrificio (Anders y Jansen 1993, p. 174 ; p. ej., Borgia 1993, pp. 18-19 ; Nuttall 1992, p. 21). En los códices por su parte aparecen templos cuyas plataformas son blancas y están rayadas de rojo (p. ej., Borgia 1993, pp. 3, 49-50 ; Vaticamus B 1993, pp. 15, 19). Es decir, este patrón rojiblanco ocurría en diferentes contextos - en dioses, en ceremonias de sacrificio y en templos - por lo que parece referir a un concepto religioso amplio. Una posibilidad es que representaba papeles goteados de sangre, una ofrenda de sacrificio bien documentada en la región nahua (Motolinía 1988, p. 87 ; Sahagún 1997, p. 74). En los códices ocurren papeles blancos con líneas rojas que parecen ser esos papeles de ofrenda (p. ej., Nuttall 1992, p. 44 ; Selden 1964, p. 2), y vasijas que llevan esos mismos papeles rayados (Borgia 1993, pp. 63, 65). En esas vasijas del Borgia se nota con claridad que las rayas rojas están sobre papel, pues éste tiene los ganchitos que indican papel cortado con la punta de la obsidiana (Sullivan 1997, p. 111). Así, las franjas rojas sobre blanco, tanto en las vasijas como en otros contextos, pudieron indicar ofrenda de sacrificio, devoción en la que se enfatiza el aspecto de ofrenda de sangre. En las vasijas, sobre esa banda rojiblanca aparece uno o varios ojos estelares; estos suelen indicar noche y oscuridad, la atmósfera misteriosa de los dioses y del trance (Anders y Jansen 1993, p. 229 ; Jansen 1998, p. 294). Por lo que en este caso pueden significar que la ofrenda de sacrificio se rodea de un ambiente de oscuridad y misterio. 


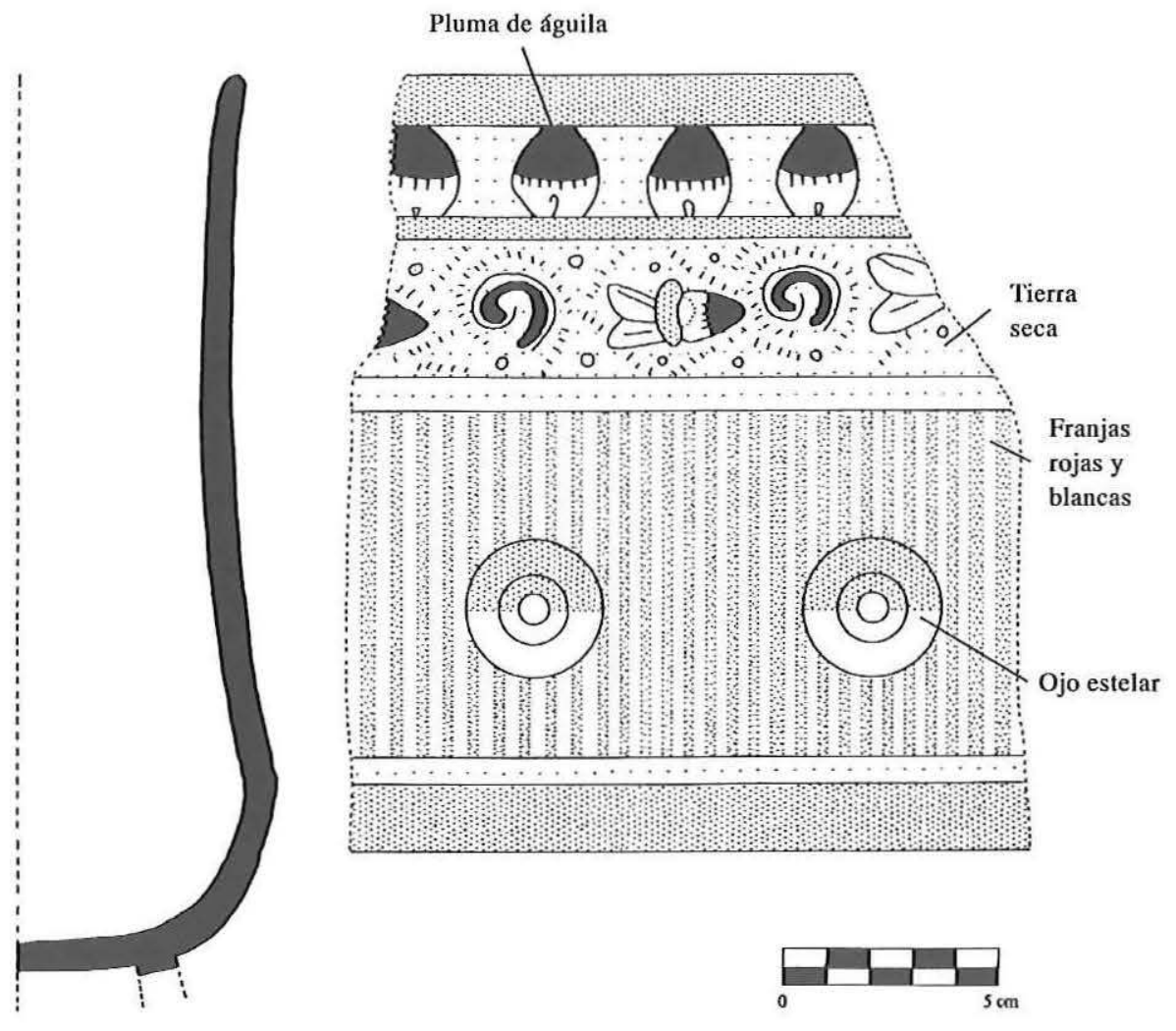

FIG. 11 - Vaso bicónico de Ocotelulco con iconografia del complejo de Ofrenda a la Tierra. Depositado en el centro INAH de Tlaxcala (clave 10-356283). Es la misma leyenda de color que en la Figura 4.

En conjunto, la iconografía parece referir a una ofrenda de sangre para la tierra seca y dañada en un contexto de oscuridad y misterio. Así, es posible que las vasijas de este complejo se involucraban en ceremonias de fertilidad agrícola. Las formas son vasos, incensarios y sahumadores. Esto sugiere que las actividades rituales para proteger la tierra de labranza involucraban la bebida de algún líquido, como señalan los vasos, y la ofrenda de humo, como evidencian los incensarios.

\section{COMPLEJO DE HUMO Y OSCURIDAD}

Aquí se agrupan 29 vasijas que vienen del valle de Puebla-Tlaxcala, Oaxaca y Veracruz. Sus formas son : copa (41.38\%), cajete trípode evertido (13.79\%), olla 


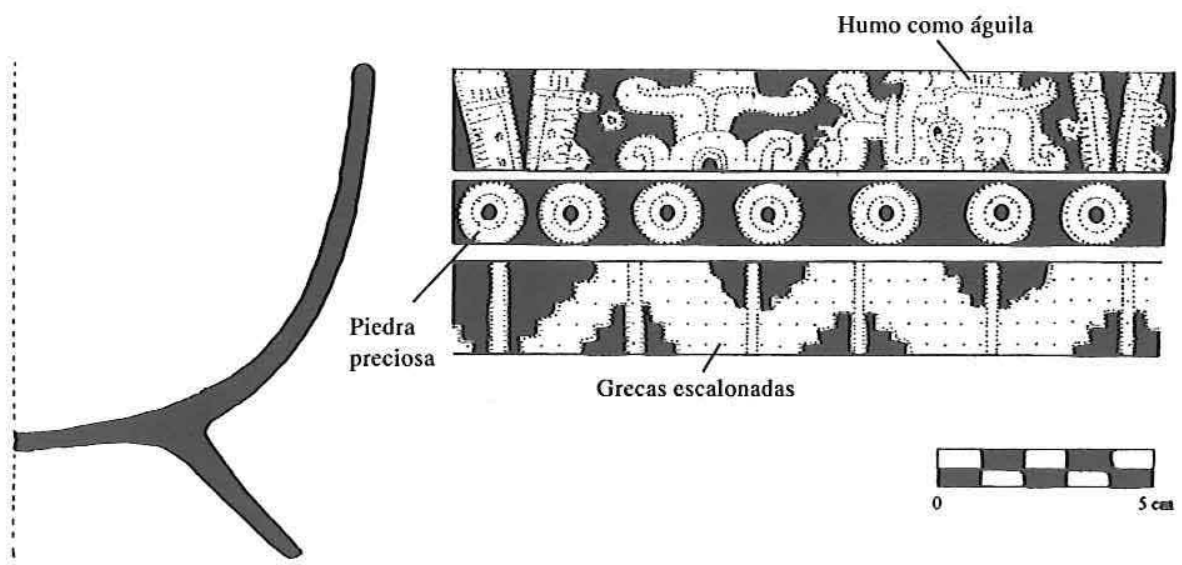

FIG. 12 - Copa de Cholula con iconografia del complejo de Humo y Oscuridad. Depositada en el Ethnologisches Museum de Berlín (clave IV Ca 7895). Es la misma leyenda de color que en la Figura 4.

(13.79\%), ollita trípode $(13.79 \%)$, incensario $(6.90 \%)$, apaxtle (6.90\%) y vaso trípode $(3.45 \%)$. Se caracterizan por tener bandas con volutas onduladas, en naranja sobre negro, que pueden representar humo, pues son similares a la manera en que éste se pinta en los códices (p. ej., Borbonicus 1991, p. 5 ; Cospi 1994, p. 12 ; Vaticamus B 1993, p. 31 ; Vindobonensis 1992, p. 6) (Figura 12). En algunas vasijas, varias volutas forman cabezas estilizadas de águila, serpiente $o$ jaguar (Figura 13), que podrían referir a que el humo tomaba esas formas.

En el Borgia (1993, pp. 9, 20, 61, 68) aparecen varias veces volutas como de humo, anaranjadas con las manchas del jaguar, un fleco de pelo blanco y ojos con ceja que podrían representar humo en forma de jaguar. También, en un monumento de piedra de Huilocintla, Veracruz, reportado por Seler $(1908$, p. 2) aparece una serpiente con volutas en el cuerpo en una escena donde un personaje se punza la lengua en autosacrificio. Y en el Dintel 15 de Yaxchilán una serpiente con volutas emerge de una vasija con papeles con sangre de autosacrificio (Furst 1976, p. 186). Ambas pudieron ser serpientes de visión que se veían como serpientes de humo. Así, una posibilidad es que en las vasijas se representó al humo en forma de esos animales. Quizá esto tenía que ver con la idea mesoamericana de que en el humo de ofrenda podían verse los dioses o antepasados a los que éste se dedicaba (Miller y Taube 1993, p. 99).

El arreglo típico de las vasijas de este grupo consiste en una banda cerca del borde con volutas de humo en color naranja sobre fondo negro. Éstas pueden ser simples o tener forma de serpiente, águila o jaguar. Algunas vasijas sólo llevan esa banda, mientras que otras muestran una o varias más. Estas otras bandas pueden ser de xicalcoliuhqui y/o de grecas escalonadas y/o de piedras preciosas y/o de 


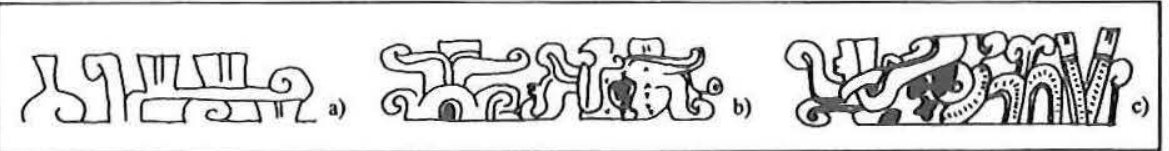

FIG. 13 - Volutas de humo en vasijas del complejo de Humo y Oscuridad : a) volutas de mandibula de serpiente, b) volutas de águila, c) volutas de jaguar. Es la misma leyenda de color que en la Figura 4.

volutas en forma de « $\mathrm{S}$ » conocidas como xonecuilli. Todas en naranja sobre fondo negro. Estas bandas indican preciosidad y nobleza, con excepción quizá de la de xonecuilli ${ }^{8}$. En conjunto la iconografía parece referir a humo, a preciosidad y a nobleza. El fondo de color negro relaciona estos conceptos a un ambiente de oscuridad y misterio.

Sahagún (1992, II, Ap. 3, pp. 164-165) menciona que quemar resinas u otros materiales era una ofrenda preciada y parte esencial de muchas ceremonias. Así, el humo en las vasijas pudo referir a ofrenda, a devoción y a ceremonia. También, el copal se consideraba el alimento de los dioses (Olivier 2003, p. 224), por lo que el humo pintado pudo igualmente tener ese significado. El humo además era el medio de contacto con los dioses y con el más allá, como deja ver la descripción de Durán (1967, I, p. 41) de un ritual cotidiano de incienso :

[...] las llevaban con aquel ídolo encima en procesión por dentro del circuito del patio, llevando delante de sí dos sacerdotes con dos braseros o incensarios de barro, incensando al ídolo, yendo y viniendo muy a menudo a incensarle. Donde cada vez que echaba aquel incienso, alzaba el brazo en alto, tanto cuanto podía extenderlo, haciendo aquella ceremonia al ídolo y al sol, pidiéndoles subiesen sus ruegos y peticiones al cielo, como subía aquel humo odorífero a lo alto.

Entonces en las vasijas el humo pudo aludir al contacto entre los dioses y los humanos, pues era el que llevaba las súplicas y propiciaba ese encuentro. Por otra parte, humo y niebla formaban un difrasismo para referir a fama y honor (Sahagún 1969, p. 244). Así, la banda de humo en las vasijas pudo simbolizar este conjunto de significados relacionados como ofrenda, ceremonia, el alimento de los dioses, el medio de contacto con lo divino y el más allá ; y quizá, fama y honor.

En breve, la iconografía de este complejo refiere a humo, a nobleza y a preciosidad. Sin embargo, esto no implica que en las vasijas mismas se producía humo. La mayoría de ellas tienen formas que no fueron diseñadas para sahumar como las copas, las ollas, los vasos, los cajetes evertidos o los platos. Más bien, las bandas de humo pudieron referir a ofrenda, a devoción, a ceremonia, a alimento divino y al encuentro con los dioses ; y por tanto señalar que las vasijas eran parte de rituales donde se buscaba el contacto con los dioses. El que el humo se representó sobre un fondo de color oscuro parece indicar que esas ceremonias 
se daban en un contexto de oscuridad y misterio, que era el ambiente de los dioses.

\section{CONSIDERACIONES FINALES}

En los cuatro grupos de vasijas descritos se distingue que hay complejos de motivos con un arreglo estándar que parecen referir a conceptos asociados con temas rituales específicos. Con base en la iconografía y en información colonial temprana aquí se propone una interpretación para cada complejo, teniendo en cuenta que la iconografía Mixteca-Puebla permite varios niveles de lectura. Las vasijas del complejo de Banda Solar referían a la purificación ritual en relación con el sol ; las de Plegaria a los Difuntos aludían a los difuntos en un ambiente de oscuridad y en relación con Tezcatlipoca ; las de Ofrenda a la Tierra mencionaban una ofrenda de sangre para la tierra seca, y las de Humo y Oscuridad indicaban el contacto entre los humanos y los dioses en un contexto de oscuridad. Estos cuatro temas representan conceptos esenciales de varias de las más comunes actividades rituales en Mesoamérica, por lo que es de suponer que aludían el uso ceremonial de las vasijas.

Las vasijas, a diferencia de los códices, parecen haber sido un género dirigido al gran público. La pictografía es relativamente sencilla comparada con los códices, y su distribución arqueológica sugiere que aunque eran artefactos escasos, no eran muy restringidos, ya que se han hallado tanto en áreas ceremoniales como habitacionales. El que en las vasijas se hayan pintado alusiones a su uso ritual con una iconografía sencilla y fácil de entender sugiere que eran objetos creados para una actividad ceremonial que debía ser identificada por cualquiera.

Llama la atención que las formas de vasija más frecuentes en el complejo de Banda Solar son platos (45.65\%) y cajetes evertidos $(28.26 \%)$, que son formas que por su diseño pueden contener comida u ofrendas sólidas, como papeles o espinas. En cambio, el vaso es la forma más frecuente en el complejo de Plegaria a los Difuntos $(76.47 \%$ ) y en el de Ofrenda a la Tierra $(66.6 \%)$, cuya función es contener líquidos para consumo individual. Esto sugiere que las ceremonias a las que se aludía en estos tres grupos de vasijas involucraban diferentes actividades. Para la devoción en relación con el sol podían hacerse ofrendas sólidas o de unas gotas de líquido, mientras que la veneración a los difuntos y antepasados, y la ofrenda a la tierra incluían la bebida de algún líquido.

Cholula es el sitio de procedencia más común de la muestra ; un $24.44 \%$ de las vasijas vienen de ahí. Esto concuerda con el carácter religioso de la ciudad, pues seguramente las actividades rituales a las que parece referirse en las vasijas como purificación ritual, culto a los difuntos, ritos de fertilidad y ofrenda de humo, eran más frecuentes ahí que en otros lugares. Sin embargo, el hecho de que en otros sitios en Puebla, Tlaxcala, Oaxaca y Veracruz también aparezca esta cerámica ${ }^{9}$ 
con un arreglo de motivos similar, sugiere que en esas tres regiones había una iconografía compartida para designar prácticas rituales comunes.

Ese sistema de motivos común es lo que se conoce como estilo MixtecaPuebla, que debió ser la manifestación de una tradición religiosa que se expresó en los códices del Grupo Borgia, en pintura mural y en la cerámica polícroma " tipo códice». *

* Manuscrit reçu en février 2004, accepté pour publication en novembre 2004.

\section{NOTAS}

1. Este trabajo es parte de un proyecto doctoral en la Onderzoekschool CNWS de la Universidad de Leiden apoyado por becas de ese instituto y de CONACYT. Mucho agradezco la guía de mis maestros Maarten Jansen y Patricia Plunket ; una buena parte de las ideas aquí presentadas vienen de discusiones con ellos. Michael Lind me dio amablemente valiosa orientación, y copias de su colección de fotografias de vasijas « tipo códice ». Gracias a Helga Giovannini y Michael Swanton por sugerir útiles mejoras al documento, $\mathrm{y}$ a los lectores anónimos por sus valiosas recomendaciones.

2. Agradezco las facilidades para consultar y registrar vasijas en el laboratorio de Arqueología de la Universidad de las Américas-Puebla, los centros INAH de Puebla, Tlaxcala y Veracruz, el Museo de las Culturas de Oaxaca, el Museo Rufino Tamayo en Oaxaca, el Museo de Antropología de Jalapa, el Museo del Templo Mayor, el Museo Nacional de Antropología, el Ethnologisches Museum en Berlín, el Museum für Völkerkunde en Münich, el Museum für Völkerkunde en Frankfurt, el British Museum, el Tropenmuseum en Amsterdam, el Rijksmuseum voor Volkenkunde en Leiden y el Museum für Völkerkunde en Viena.

3. En la muestra 251 vasijas $(61.97 \%)$ están completas.

4. Peperstraete (2002, p. 13) sugiere que este motivo evoca la representación del agua y las plumas del ave chalchiuhtotolin ; también reconoce que aparece en el ceñidor de Tezcatlipoca en el Borgia por lo que debió aludir a ese dios.

5. Cecelia Klein (2000, p. 21$)$ sugiere que estas capas tenían propiedades mágicas curativas.

6. Aunque en el altar de la estructura hay otros motivos que no aparecen en la cerámica, es claro que el tema en ambos es el mismo. Siguiendo a Contreras (1994a, p. 111), en las paredes del altar, sobre el patrón de franjas negras sobre blanco, hay ocho serpientes de fuego, xiullcoatl en náhuatl, que descienden en corrientes de sangre hacia la base del altar. También, en la pared frontal del altar hay un rectángulo rodeado de pedernales que al centro tiene un brasero. Sobre éste, hay un pedernal grande del que sale el rostro de Tezcatlipoca. Este rectángulo es similar a la página 32 del Codex Borgia (1993) donde se describe un ritual en un lugar rodeado de pedernales y oscuridad.

7. De sólo una de las vasijas de este complejo se conoce su contexto arqueológico específico. Se trata de un cajete trípode evertido de Ocotelulco hallado sobre un tlecuil (o hogar) en uno de los cuartos inmediatamente al norte de las estructuras policromas (Palavicini y Contreras 1994, pp. 99-100).

8. Con el nombre de xonecuilli se llamaba una constelación que tenía forma de « $\mathrm{S}$ » y unos panes con el mismo diseño que se ofrendaban a varios dioses y que se decía representaban rayos del cielo (Sahagún 1992, VII, Cap. 4, p. 435 ; I, Cap. 10, p. 35).

9. Hector Neff y colaboradores (1994) realizaron un análisis de activación neutrónica de las pastas de una muestra de vasijas " tipo códice » de varios sitios del centro de Mesoamérica. Los resultados indican la existencia de muchos centros de producción de esta cerámica en el Postclásico Tardío como Cholula, Huejotzingo, Tizatlán-Ocotelulco, Taxqueña en la cuenca de México y la Mixteca. 


\section{BIBLIOGRAFÍA}

\section{Aguilera Carmen}

1978 Coyolxauhqui. Ensayo iconográfico, Biblioteca Nacional de Antropología e Historia, México.

1988 Comentario al Códice Cospi : calendario messicano 4093, Biblioteca Universitaria de Bolonia/Centro Regional de Puebla, Puebla.

ANDERs Ferdinand y Maarten JANSEN

1993 Manual del Adivino. Libro explicativo del llamado Códice Vaticano B, Akademische Druck -u. Verlagsanstalt/Fondo de Cultura Económica, Graz/ México.

Anders Ferdinand, Maarten JANSEn y Gabina Aurora PéreZ JiMÉneZ

1992a Crónica Mixteca. El rey \& Venado, Garra de Jaguar, y la dinastía de Teozacualco-Zaachila. Libro explicativo del llamado Códice Zouche-Nuttall, Akademische Druck - u. Verlagsanstalt/Fondo de Cultura Económica, Graz/México.

1992b Origen e historia de los reyes mixtecos. Libro explicativo del llamado Códice Vindobonensis, Akademische Druck - $\mathrm{u}$. Verlagsanstalt/Fondo de Cultura Económica, Graz/México.

1994 El Libro de Tezcatlipoca, Señor del tiempo. Libro explicativo del llamado Códice Fejérváry-Mayer, Akademische Druck -u. Verlagsanstalt/Fondo de Cultura Económica, Graz/México.

Anders Ferdinand, Maarten JANSEn y Luis Reyes García

1991 El Libro del Cihuacoatl. Homenaje para el año del fuego nuevo. Libro explicativo del llamado Códice Borbónico, Akademische Druck -u. Verlagsanstalt/

1993 Los Templos del cielo y de la oscuridad. Oráculos y liturgia. Libro explicativo del llamado Códice Borgia, Akademische Druck -u. Verlagsanstalt/Fondo de Cultura Económica, Graz/México.

ANDERs Ferdinand, Maarten JANSEN y Peter VAN DER Loo

1994 Calendario de pronósticos y ofrendas. Libro explicativo del llamado Códice Cospi, Akademische Druck -u. Verlagsanstalt/Fondo de Cultura Económica, Graz/México.

Berdan Frances y Patricia Anawalt

1992 The Codex Mendoza, University of California Press, Berkeley.

1997 The essential Codex Mendoza, University of California Press, Berkeley.

BEYER Hermann

1965 «Hermann Beyer. Obras completas, tomo I », El México Antiguo, X, Sociedad Alemana Mexicanista, México.

1969 "Explicación de un fragmento de un antiguo plato decorado de Cholula », El México Antiguo, XI, pp. 450-470, Sociedad Alemana Mexicanista, México. 
Boone Elizabeth $\mathrm{H}$.

2000 Stories in red and black. Pictorial histories of the Aztecs and Mixtecs, University of Texas Press, Austin.

Carrasco Pedro

1971 "The people of central Mexico and their historical traditions", in G. Ekholm e I. Bernal, eds, Handbook of Middle American Indians, vol. 11, Archaeology of Northern Mesoamerica, Part 2, pp. 459-473, University of Texas Press, Austin.

Caso Alfonso

1927 "Las ruinas de Tizatlán, Tlaxcala », Revista Mexicana de Estudios Históri$\cos , 1$ (4), pp. 1-34.

1964 Códice Selden 3135(A.2), Sociedad Mexicana de Antropología, México.

Chadwick Robert

1971 "Postclasssic pottery of the Central Valleys », in G. Ekholm e I. Bernal, eds, Handbook of Middle American Indians, vol. 10, Archaeology of Northern Mesoamerica, Part 1, pp. 228-257, University of Texas Press, Austin.

Codex Borbonicus

1991 ver ANDERs, Jansen y Reyes García.

Codex Borgia

1993 ver ANDERS, JANSEN y REyes García.

Codex Cospi

1994 ver ANDERs, JANSEN y VAN Der LoO.

Codex Fejérváry-Mayer

1994 ver ANDERS, JANSEN y PÉREZ JiMÉNEZ.

Codex Magliabechi

1983 ver NutTall.

Codex Mendoza

1992 ver Berdan y ANawalt.

Codex Nuttall

1992a ver Anders, Jansen y Peréz Jiménez.

Codex Selden

1964 ver Caso.

Codex Vaticanus B

1993 ver ANDERS Y JANSEN.

Codex Vindobonensis

1992b ver ANders, JANSEn y Pérez Jiménez.

CONTRERAs Eduardo

1994a «Las estructuras polícromas de Ocotelulco, Tlaxcala. Arquitectura, historia y descripción ", in F. Anders, M. Jansen y P. van der Loo, eds, Calendario de pronósticos y ofrendas. Libro explicativo del llamado Códice Cospi, pp. 109-117, Akademische Druck -u. Verlagsanstalt/Fondo de Cultura Económica, Graz/México. 
1994b «Los murales y cerámica polícromos de la zona arqueológica de Ocotelulco, Tlaxcala », in H. B. Nicholson y E. Quiñones, eds, Mixteca-Puebla. Discoveries and research in Mesoamerican art and archaeology, pp. 7-24, Labyrinthos, Culver City.

Díaz del CASTiLlo Bernal

1938 [1632] Historia de la conquista de la Nueva España, 2 vols, Publicaciones Herrerías, México.

DiBBLE Charles

1971 "Writing in Central Mexico », in G. Ekholm e I. Bernal, eds, Handbook of Middle American Indians, vol. 10, Archaeology of Northern Mesoamerica, Part 1, pp. 322-332, University of Texas Press, Austin.

DuRÁn Fray Diego

1967 Historia de las indias de Nueva España e Islas de Tierra Firme, 2 vols, Editorial Porrúa, México.

1980 Ritos y fiestas de los antiguos mexicanos, Editorial Innovación, México.

Furst Peter

1976 "Fertility, vision quest and auto-sacrifice : some thoughts on ritual bloodletting among the Maya ", in M. Greene Robertson, ed., The Art, iconography and dynastic history of Palenque, Part III. Proceedings of the Segunda Mesa Redonda de Palenque, pp. 181-193, Precolumbian Art Research, Peeble Beach.

Garibay Ángel María

1992 «Vocabulario. De las palabras y frases en lengua náhuatl que usa Sahagún en su obra ", in A. M. Garibay, ed., Historia general de las cosas de Nueva España, pp. 911-963, Editorial Porrúa, México.

GiBson Charles

1952 Tlaxcala in the sixteenth century, Yale University Press, New Haven.

JANSEN Maarten

1982 Huisi Tacu. Estudio interpretativo de un libro Mixteco antiguo : Codex Vindobonensis Mexicanus I, CEDLA, Amsterdam.

1997 "La serpiente emplumada y el amanecer de la historia », in M. Jansen y L. Reyes García, eds, Códices, caciques y comunidades, Cuadernos de la Historia Latinoamericana, 5, pp. 11-63, Asociación de Historiadores Latinoamericanistas Europeos, Ridderkerk.

1998 "Ein Blick in den Tempel von Cihuacoatl. Zur Religiösen Funktion der Codices aus Zentralmexiko », in C. Arellano y P. Schmidt, eds, Die Bücher der Maya, Mixteken und Azteken. Die Schrift und ihre Funktion in Vorspanischen und Kolonialen Codices, pp. 257-306, Vervuert Verlag, Frankfurt am Main.

JANSEn Maarten y Gabina Aurora Pérez Jiménez

2000 La Dinastía de Añute. Historia, literatura e ideología de un reino Mixteco, CNWS, Universiteit Leiden, Leiden. 
KLeIN Cecelia

2000 "The devil and the skirt. An iconographic inquiry into the pre-hispanic nature of the Tzitzime ", Ancient Mesoamerica, 11, pp. 1-26.

LiND Michael

1967 Mixtec polychrome pottery : a comparison of the late preconquest polychrome pottery from Cholula, Oaxaca, and the Chinantla, tesis de maestría inédita, Universidad de las Américas, Cholula.

1994 "Cholula and Mixteca polychromes : two Mixteca-Puebla regional substyles ", in H. Nicholson y E. Quiñones, eds, Mixteca-Puebla. Discoveries and research in mesoamerican art and archaeology, pp. 79-99, Labyrinthos, Culver City.

López Austin Alfredo

1996 Cuerpo humano e ideología. Las concepciones de los antiguos nahuas, 2 vols, Universidad Nacional Autónoma de México, México.

Matos Moctezuma Eduardo

1988 The Great temple of the Aztecs. Treasures of Tenochtitlan, Thames and Hudson, London.

MCANANY Patricia

1995 Living with the ancestors. Kinship and kingship in ancient Maya society, University of Texas Press, Austin.

MCCAFFERTY Geoffrey

1994 "The Mixteca-Puebla stylistic tradition at early postclassic Cholula », in H. B. Nicholson y E. Quiñones, eds, Mixteca-Puebla. Discoveries and research in Mesoamerican art and archaeology, pp. 53-77, Labyrinthos, Culver City.

Miller Mary Ellen y Karl Taube

1993 Gods and symbols of the ancient Mexico and the Maya, Thames and Hudson, New York.

Motolinía Fray Toribio de Benavente

$1988 \quad$ Historia de los indios de la Nueva España, Alianza Editorial, Madrid.

MüLLER Florencia

1970 "La cerámica de Cholula », in I. Marquina, ed., Proyecto Cholula, pp. 129142, Instituto Nacional de Antropología e Historia, México.

1978 La Alfarería de Cholula, Secretaría de Educación Pública/Instituto Nacional de Antropología e Historia, México.

NefF Hector, Ronald Bishop, Edward Sisson, Michael Glascock y Penny Sisson

1994 «Neutron activation analysis of late postclassic polychrome pottery from Central Mexico ", in H. B. Nicholson y E. Quiñones, eds, Mixteca-Puebla. Discoveries and research in Mesoamerican art and archaeology, pp. 119-141, Labyrinthos, Culver City.

Nicholson Henry B.

1966 "The Mixteca-Puebla concept in Mesoamerican archaeology : a Reexamination ", in J. Graham, ed., Ancient Mesoamerica, pp. 258-263, Peek Publications, Palo Alto. 
1971 «Religion in pre-hispanic Central Mexico », in G. Ekholm e I. Bernal, eds, Handbook of Middle American Indians, vol. 10, Archaeology of Northern Mesoamerica, Part 1, pp. 395-445, University of Texas Press, Austin.

1982 "The Mixteca-Puebla concept revisited », in E. H. Boone, ed., The Art and iconography of Late Postclassic Central Mexico, pp. 227-254, Dumbarton Oaks Research Library and Collections, Washington, D.C.

1994 «The eagle claw/tied double ear motif : the Cholula polychrome ceramic tradition and some members of the Codex Borgia group ", in H. B. Nicholson y E. Quiñones, eds, Mixteca-Puebla. Discoveries and research in Mesoamerican art and archaeology, pp. 101-116, Labyrinthos, Culver City.

Nicholson Henry B. y Eloise QuiÑones

1983 Art of Aztec Mexico. Treasures of Tenochtitlan, National Gallery of Art, Washington, D.C.

1994 "Introduction », in H. B. Nicholson y E. Quiñones, eds, Mixteca-Puebla. Discoveries and research in Mesoamerican art and archaeology, pp. vii-xv, Labyrinthos, Culver City.

NutTall Zelia

1983 The Book of the life of the ancient Mexicans, University of California, Berkeley.

OLIVIer Guilhem

2003 Mockeries and metamorphoses of an Aztec god. Tezcatlipoca, "Lord of the smoking mirror », University Press of Colorado, Boulder.

Peperstraete Sylvie

2002 "Les peintures d'Ocotelulco et le problème de la provenance du Codex Borgia ", Annales d'Histoire de l'Art et d'Archéologie, 24, pp. 7-25.

\section{Palavicini Beatriz y Eduardo Contreras}

1994 "Un cajete polícromo tipo Códice, de Ocotelulco, Tlaxcala », in F. Anders, M. Jansen y P. Van der Loo, eds, Calendario de pronósticos y ofrendas. Libro explicativo del llamado Códice Cospi, pp. 99-107, Akademische Druck -u. Verlagsanstalt/Fondo de Cultura Económica, Graz/México.

PoHL John

1998 "Themes of drunkenness, violence, and factionalism in Tlaxcalan Altar paintings ", Res, 33, pp. 185-207.

\section{QUIÑONES Eloise}

1994 "The Codex style: which Codex? which style? », in H. B. Nicholson y E. Quiñones, eds, Mixteca-Puebla. Discoveries and research in Mesoamerican art and archaeology, pp. 143-152, Labyrinthos, Culver City.

RAMSEY James

1975 An analysis of Mixtec minor art, with a catalogue, Ph. D., Tulane University, New Orleans.

1982 "An examination of Mixtec iconography ", in D. Stone, ed, Aspects of the Mixteca-Puebla style and Mixtec and Central Mexican culture in Southern Mesoamerica, pp. 33-43, Occasional Paper, 4, Middle American Research Institute, New Orleans. 


\section{ROBERTSON Donald}

1961 "The style of the Borgia Group of Mexican pre-conquest manuscripts », in Proceedings of the XXth International Congress of the History of Art (New York).

Rojas Gabriel de

1985 «Relación de Cholula », in R. Acuña, ed, Relaciones geográficas del siglo XvI : Tlaxcala, vol. II, pp. 125-145, Universidad Nacional Autónoma de México, México.

SAHAGÚn Fray Bernardino de

1969 Florentine Codex. General history of the things of New Spain, Book II, Rhetoric and moral philosophy, traducido por A. J. O. Anderson y C. E. Dibble, The School of American Research/The University of Utah, Santa Fe.

1992 Historia general de las cosas de la Nueva España, ed. por A. M. Garibay, Editorial Porrúa, México.

1997 Primeros Memoriales, traducido por T. Sullivan, University of Oklahoma Press, Norman.

SELER Eduard

1908 Gesammelte Abhandlungen zur amerikanischen Sprach-und Altertumskunde, vol. 3, Behrend \& Co., Berlin.

1963 Comentarios al Códice Borgia, 2 vols, Fondo de Cultura Económica, México.

Sisson Edward y Gerald LiLLY

1994 "The mural of the Chimales and the Codex Borgia », in H. B. Nicholson y E. Quiñones, eds, Mixteca-Puebla. Discoveries and research in Mesoamerican art and archaeology, pp. 25-44, Labyrinthos, Culver City.

SHARP Rosemary

1981 Chaacs and chiefs, Dumbarton Oaks, Washington, D.C., coll. " Studies in Precolumbian Art and Archaeology » 24.

Smith, Michael y Cynthia Heath-Smith

1980 "Waves of influence in Postclassic Mesoamerica? A critique of the Mixteca-Puebla concept ", Anthropology, 4 (2), pp. 15-50.

SoLís Felipe

1995 «Pintura mural en el Altiplano Central », Arqueología Mexicana, 3 (16), pp. $30-35$.

Sullivan Thelma

1997 Primeros memoriales by Fray Bernardino de Sahagún. Paleography of Nahuatl text and English translation, University of Oklahoma Press, Norman.

Torquemada Fray Juan de

1969 Monarquía indiana, 2 vols, Editorial Porrúa, México.

TOWNSEND Richard

1992 The Aztecs, Thames and Hudson, London.

WORLD LÄNDERKARTE

1998 World Länderkarte, RV Verlag, Stuttgart. 